\title{
Agrupació i segregació espacial de la població de nacionalitat marroquina a Tarragona, 2004-2012
}

\author{
Hicham Achebak \\ Universitat Rovira i Virgili \\ hicham.achebak@gmail.com \\ Joan Alberich González \\ Universitat Rovira i Virgili. Departament de Geografia \\ joan.alberich@urv.cat
}

Recepció: octubre de 2013

Acceptació: abril de 2014

\section{Resum}

La ciutat de Tarragona es caracteritza per ser un dels principals pols d'assentament de la població de nacionalitat marroquina a Catalunya. Des d'inicis del segle XxI, aquesta població ha protagonitzat un important creixement que la situa a la capçalera del rànquing de nacionalitats estrangeres del municipi. Paral-lelament a l'augment del nombre d'efectius, el col-lectiu ha experimentat canvis substancials en la seva distribució espacial. L'objectiu d'aquest treball és precisament analitzar l'evolució de les pautes d'assentament i els nivells de segregació residencial de la comunitat marroquina a l'interior de l'espai urbà tarragoní corresponents al període temporal 2004-2012 a partir de les dades del Padró Municipal d'habitants.

Paraules clau: població de nacionalitat marroquina; Tarragona; distribució espacial; segregació residencial.

Resumen. Agrupación y segregación espacial de la población de nacionalidad marroqui en Tarragona, 2004-2012

La ciudad de Tarragona se caracteriza por ser uno de los principales polos de asentamiento de la población de nacionalidad marroquí en Cataluña. Desde inicios del siglo Xxi, esta población ha protagonizado un importante crecimiento que la sitúa en la cabecera del ranking de nacionalidades extranjeras del municipio. De forma paralela al aumento del nombre de efectivos, el colectivo ha experimentado cambios sustanciales en su distribución espacial. El objetivo de este trabajo es precisamente analizar la evolución de las pautas de asentamiento y los niveles segregación residencial de la comunidad marroquí en el interior del espacio urbano tarraconense correspondientes al período temporal 2004-2012 a partir del los datos del Padrón Municipal de habitantes.

Palabras clave: población de nacionalidad marroquí; Tarragona; distribución espacial; segregación residencial. 
Résumé. Regroupement et ségrégation spatiale de la population de nationalité marocaine à Tarragone, 2004-2012

La ville de Tarragone est caractérisée par l'existence d'un des principaux pôles d'établissement de la population de nationalité marocaine en Catalogne. Dès le début du xxième siècle, on a pu observer une croissance exponentielle de cette population à Tarragone, ce qui la place aujourd'hui en tête du classement des nationalités étrangères dans cette ville. Parallèlement à la croissance de cet effectif, l'ensemble a connu des changements substantiels dans sa distribution spatiale. Le principal but de cette recherche est précisément d'analyser l'évolution des règles d'établissement ainsi que les niveaux de ségrégation résidentielle de la communauté marocaine dans l'espace urbain de la ville de Tarragone, faits correspondant à la période 2004-2012 a partir des données du Recensement Municipal des habitants.

Mots-clé: population de nationalité marocaine; Tarragone; distribution spatiale; ségrégation résidentielle.

Abstract. Grouping and spatial segregation of Moroccan nationals in Tarragona, 2004-2012

The city of Tarragona is one of the main poles for the settlement of Moroccan nationals in Catalonia. Since the beginning of the $2 \mathrm{I}^{\mathrm{ST}}$ century, there has been a significant increase in this population, with Moroccans now making up the largest group in the ranking of foreign nationalities. At the same time, there have been substantial changes in the spatial distribution of this group. The main goal of this research is to analyse the evolution of the settlement patterns and the levels in residential segregation of the Moroccan community in the Tarragona urban area for the 2004-2012 period using data from Municipal Register.

Keywords: Moroccan population; Tarragona; spatial distribution; residential segregation.

\section{Sumari}

1. Presentació i objectius

2. Un breu estat de la qüestió

3. La segregació residencial: una visió panoràmica

4. Fonts estadístiques, àmbit territorial $\mathrm{i}$ indicadors de segregació residencial
5. Població marroquina a Tarragona.

Agrupació i segregació espacial

6. Conclusions

Referències bibliogràfiques

\section{Presentació i objectius}

L'objectiu d'aquest treball és analitzar l'evolució de les pautes de distribució espacial i la segregació residencial de la població de nacionalitat marroquina a l'interior de la ciutat de Tarragona corresponents al període temporal 20042012. Com es veurà a l'apartat següent, dedicat a elaborar un breu estat de la qüestió sobre la recerca en aquesta temàtica, no es tracta d'una aproximació metodològica nova, sinó de donar continuïtat a un gran nombre de treballs similars realitzats per a altres escales territorials per omplir un buit de la litera- 
tura existent (malgrat les nombroses aportacions recents): mentre que la gran majoria de les anàlisis realitzades s'han centrat en les grans ciutats, existeix una mancança preocupant de treballs sobre ciutats mitjanes i petites on, percentualment, el nombre de població nouvinguda és, en alguns casos, superior al de les grans conurbacions urbanes.

Per tal d'assolir l'objectiu plantejat, l'estudi parteix de la constatació que del començament del boom immigratori ençà, les dinàmiques residencials de la població de nacionalitat marroquina s'han caracteritzat per un imminent procés de concentració als barris periferics populars de la ciutat de Tarragona, emergits arran de la immigració procedent de la resta d'Espanya durant el transcurs del segle passat i que se situen a la part inferior de la jerarquia residencial de la ciutat. Ara bé, les qüestions que des del punt de vista espacial ens sorgeixen davant aquesta evidència són les següents: en primer lloc, aquesta distribució desigual en l'espai de la subpoblació implica un increment progressiu en la seva segregació residencial? I, en cas de ser així, existeixen pautes territorial d'assentament similars a altres col-lectius nacionals?

A fi de donar resposta a aquestes qüestions, el treball s'ha dividit en sis apartats, el primer dels quals és aquesta breu presentació de l'objectiu de l'estudi. El segon apartat consisteix en un breu estat de la qüestió en què es destaca la falta de treballs que emprin una escala d'anàlisi similar a la plantejada aquí, mentre que en el tercer es fa una reflexió teòrica sobre l'objecte d'estudi, visió que es veu complementada amb la presentació de la metodologia i els indicadors emprats, aspecte central del quart apartat.

L'anàlisi realitzada i els resultats obtinguts es presenten a l'apartat cinquè de l'article, titulat «Població marroquina a Tarragona. Agrupació i segregació espacial 2004-2012», que consta, inicialment, d'una breu presentació sobre l'evolució dels fluxos i estructura demogràfica de la població de nacionalitat marroquina; en segon terme, s'hi analitza la distribució territorial d'aquest col-lectiu a escala inframunicipal; i en últim terme, s'apliquen diferents indicadors de segregació residencial. Finalment, el sisè capítol correspon a les conclusions, en les quals es reprenen les preguntes inicials de la recerca amb l'ànim de contrastar-les i plantejar, així, algunes propostes de millora i línies futures d'investigació. El treball conclou amb la relació de referències bibliogràfiques consultades.

\section{Un breu estat de la qüestió}

Els primers estudis referits a la segregació residencial s'aborden durant els anys vint del segle passat des de l'ecologia humana i tenen els orígens en les investigacions de l'escola d'ecologia urbana de Chicago, centrades en temes racials $i$ en què destaquen autors com ara Park (1924), que ens parla de la "distància social» o la intensitat de les relacions personals; Burgess (1928), que parla sobre la segregació residencial de ciutadans segons la seva raça en ciutats americanes, i Wirth (1928), que tracta els guetos de ciutadans jueus.

No obstant això, haurem d'esperar fins als anys quaranta per trobar els primers treballs que ens proposin els primers indicadors destinats a plasmar 
quantitativament l'abast i l'evolució del fenomen de la segregació residencial, aspecte en què destaquen els estudis sobre els índexs d'igualtat de Duncan i Duncan (1955a i 1955b) i els índexs d'interacció de Bell (1954). Durant els anys vuitanta i noranta, altres autors americans (Morgan; 1975; Jakubs, 1981; White, 1983; Morrill, 1991; i Wong, 1993) van elaborar els índexs espacials de segregació residencial, que fan possible la classificació i comparabilitat de la situació dels diferents grups de població de les ciutats i permeten efectuar anàlisis temporals.

A Europa els estudis sobre segregació residencial es troben fortament influenciats per les investigacions anteriors existents als EUA, i no despertaran un cert interès fins a mitjan dècada dels setanta, sobretot des de les institucions polítiques, quan els guestworkers no mostraven intenció de tornar als seus països d'origen (Bolt et al., 2002). És sobretot al sud d'Europa, pel seu paper com a zona receptora d'un gran nombre d'immigrants a la darrera dècada del segle xx i la primera del XxI, on més han proliferat els estudis acadèmics (generalistes alguns, i d'anàlisi de casos concrets, uns altres) sobre el tema: a França destaca l'estudi de Guermond i Lajoie (1999) sobre la segregació a les ciutats franceses; a Portugal, els treballs de Malhieros sobre el paper dels països del sud d'Europa (Grècia, Itàlia, Portugal i Espanya) en els sistemes internacionals de migració i en l'aparició de nous patrons de segregació ètnica (Malheiros, 2002) i sobre el cas particular de la ciutat de Lisboa (Malheiros, 2004); a Itàlia, els treballs d'Arbaci sobre la situació comparativa a diverses ciutats del sud d'Europa, com ara Barcelona (Arbaci 2007, 2008; Arbaci i Malheiros, 2010), temes que també són tractats pel grec Maloutas (Maloutas i Fujita, 2012).

Centrant-nos en el context espanyol i català, destaquen diversos estudis sobre les grans ciutats, ja que principalment és en aquests contextos urbans on s'ha assentat la major part de la població estrangera els darrers anys. Així, trobem estudis similars per a les ciutats de Madrid (Martínez i Leal, 2008; Echazarra, 2009, 2010), Barcelona (Bayona i Blanco, 2004; Bayona, 2007a i 2007b; Bayona i López, 2011), Bilbao (Lavía, 2008; 2009) i diverses ciutats andaluses (Checa i Arjona, 2007; Checa et al., 2011), amb l'objectiu comú de quantificar la segregació residencial de la població estrangera a partir d'alguns dels indicadors anteriorment esmentats, buscar-ne els factors explicatius $i$, en alguns casos, fer recomanacions per al disseny de polítiques públiques.

Com s'ha pogut comprovar, i com avançàvem inicialment, el gruix dels treballs se centra en les grans ciutats, mentre que només Martori i Hoberg (2008) trenquen aquest esquema i amplien l'anàlisi de la segregació residencial a tots els municipis adjacents a la capital catalana (Santa Coloma de Gramenet, Badalona, Sant Adrià de Besòs, l'Hospitalet de Llobregat, Cornellà de Llobregat i el Prat de Llobregat), i més recentment cal destacar l'exhaustiu treball del Grup d'Estudis Demogràfics i de les Migracions del Centre d'Estudis Demogràfics (Sabater et al., 2012, 2013). En aquest sentit, el present text pretén omplir un buit existent pel que fa als estudis de distribució i segregació espacial de les poblacions estrangeres a les principals ciutats catalanes. 


\section{La segregació residencial: una visió panoràmica}

\subsection{El concepte de segregació}

Què s'entén per segregació? El concepte de segregació comprèn multiplicitat de sentits, significats, connotacions i aplicacions diverses. White (1983) defineix el concepte des de dues visions científiques diferents: l'òptica sociològica i la geogràfica. En el sentit sociològic, la noció de segregació es refereix a l'absència d'interacció entre grups socials, mentre que des del vessant geogràfic del terme, la segregació implica la distribució desigual dels grups socials en un espai circumscrit. En aquest mateix últim sentit, Brun (1994) ens aporta una definició on preval el sentit geogràfic del concepte: «La distinció espacial entre les àrees residencials de grups de població que viuen en una mateixa aglomeració».

Es fa necessària, per tant, la distinció entre el sentit purament espacial de «segregació residencial» i el sentit social de la segregació: els processos de diferenciació social, la marginació, la discriminació o l'exclusió. Deixant de banda el tractament qualitatiu del terme, trobem que bona part del desenvolupament teòric sobre la segregació se cenyeix a la seva mesura. La quantificació de la segregació ens proporciona un ampli ventall d'anàlisi que en permetrà la comparabilitat i l'evolució temporal.

Una de les dimensions de la segregació és la concentració espacial (Massey i Denton, 1988). La "concentració» mesura el grau d'aglomeració d'un grup de població dins d'una ciutat; és a dir, l'espai ocupat per un grup de població mesurat en termes de superfície. En aquest sentit, un col-lectiu està concentrat si ocupa una proporció petita de l'espai urbà. Si hom defineix un territori com la concentració d'un grup de població determinat, al mateix temps s'està afirmant una distribució desigual en l'espai i, per tant, implícitament, una segregació. En tot cas, tant la concentració com la segregació són símptomes de la manca d'oportunitats per a una població determinada.

\subsection{Causes i conseqüències}

Partint de la realitat urbana i social de les ciutats on vivim, es pot contemplar que la segregació és una realitat característica i natural de la ciutat capitalista. La segregació esdevé, per tant, un fet propi de la nostra identitat urbana, on l'anomalia seria la no-segregació (Fullaondo, 2008), mentre la desigualtat urbana i social es mantingui. Una de les qüestions fonamentals de la segregació és conèixer les forces que l'originen. Bayona (2007a), en el seu intent de sistematitzar la multiplicitat de causes que apareixen en la bibliografia científica, assenyala que la segregació espacial, entesa sempre des d'una òptica merament geogràfica, és el resultat de tres factors inductors: la segregació per motius socioeconòmics, per motius demogràfics i per motius ètnics o racials.

El factor socioeconòmic es relaciona amb la condició de classe desafavorida de la població immigrant, fet que provoca que la segregació socioeconòmica de la ciutat per si mateixa sigui un mecanisme important de segregació. Pel que fa al factor demogràfic, l'autor apunta que la major mobilitat residencial i l'es- 
tructura de la llar (condicionada pel mateix procés migratori) són, al mateix temps, elements que influeixen en la diferenciació residencial entre la població immigrant. Així doncs, l'evolució de la composició familiar de la llar, vinculada a la mobilitat residencial, genera diferents formes de segregació. El tercer mecanisme que pot tenir un paper decisiu en la diferenciació social de l'espai és el basat en l'etnicitat o nacionalitat. Segons Bayona (2007a), aquesta respon a dos grans grups de motius: d'una banda, a processos endògens d'agrupació i, de l'altra, a situacions de discriminació. El primer aspecte afecta en major mesura els col-lectius d'immigrants que es diferencien més de la societat d'acollida per la seva llengua, les seves pràctiques religioses o alguns altres trets culturals. En la concentració es troben menys estranys i més còmodes, ja que recreen una atmosfera social que els és familiar. L'exemple més il.lustratiu d'aquest procés d'agrupació endògena el trobem al barri del Raval (per a d'altres, «ravalkistan») de Barcelona, on es troba una forta agrupació de població magribina i pakistanesa. No obstant això, tota segregació ètnica es considera problemàtica quan aquesta es produeix en zones d'exclusió social urbana (Fullaondo, 2008). Per exemple, ningú no identifica la segregació japonesa al barri de Sarrià de Barcelona com a problemàtica; però, en el cas del barri del Raval, sí que hi té una connotació negativa. La discriminació és el principal mecanisme de segregació quan s'aconsegueixen controlar les diferències socioeconòmiques i demogràfiques, $\mathrm{i}$ es manifesta principalment en l'accés a l'habitatge.

\subsection{Entre avantatges $i$ desavantatges}

La segregació residencial presenta múltiples desavantatges per a la població immigrant $\mathrm{i}$, alhora, alguns avantatges. Pel que fa als primers, Kempen i Özüekren (1998) afirmen que la segregació dels immigrants redueix les oportunitats de participació social, cosa que suposa un menor grau de relació $\mathrm{i}$ interacció amb la societat receptora i també amb les institucions, fet que genera un major grau d'exclusió. Una altra característica negativa que es pot manifestar és la segregació escolar i en el sistema educatiu, que evidentment es deriva de la segregació residencial. Els problemes de caire lingüístic que experimenta la població immigrant, és a dir, les dificultats per parlar de manera correcta i fluïda l'idioma o idiomes del país d'acollida també suposen un desavantatge. La llengua, a més de permetre una millor comunicació i interacció social dels immigrants, és un element clau en el procés d'integració de la població nouvinguda. El darrer desavantatge que cal ressaltar és la percepció o imatge negativa que té la societat envers les zones segregades i la població que hi resideix.

No obstant això, segons els mateixos autors, la segregació també pot beneficiar en determinats aspectes els immigrants. D'una banda, permet preservar els trets culturals i els valors del col-lectiu en qüestió; això no només es reflecteix en les formes de comportament, sinó que també s'arriba a reproduir en l'espai físic (botigues, espais de trobada, centres culturals i de culte, associacions...). 
Tot plegat crea una atmosfera que els és familiar, amb la qual s'identifiquen i que els fa sentir més com a casa. En consonància amb això, la segregació també actua positivament en la generació i funcionament de les xarxes socials dels immigrants: gràcies a aquestes xarxes molts immigrants es beneficien tant en el pla personal (per exemple, poder mantenir una simple conversa) com en el de necessitat (per exemple, trobar suport en la cerca d'un pis o feina, préstec de diners...) (Fullaondo, 2008). Lògicament, la importància de les xarxes socials s'aguditza en el cas dels immigrants nouvinguts, que encara no coneixen prou bé el funcionament de la nova societat. Les xarxes socials, en molts casos, supleixen la funció de l'Estat, sobretot en el món informal en què està immersa part de la immigració.

\subsection{Concentració, gueto i enclavament ètnic}

L'espai residencial en què un grup determinat està sobrerepresentat és designat amb un ventall ampli de termes amb significats a vegades similars i d'altres dispars que no tenen perquè coincidir amb la mateixa situació. Peach (1996a) distingeix dos tipus de segregació: la voluntària ("positiva») i la imposada («negativa»); els enclavaments ètnics i els guetos. Deurloo i Musterd (1998) afegeixen una tercera forma o accepció espacial: l'àrea de concentració.

El gueto es concep com un barri on pràcticament només resideix un grup ètnic o cultural (Peach, 1996b); l'enclavament ètnic, com un districte on la presència d'un grup ètnic barrejat amb altres és dominant; i l'àrea de concentració (Deurloo i Musterd, 1998), com la zona on un col-lectiu figura en proporcions superiors a les que trobem en altres espais de la ciutat, encara que en aquesta àrea sigui una minoria.

L'anàlisi estadística de la segregació geogràfica del nostre estudi no ens permet fer afirmacions sobre si som davant d'una segregació voluntària o imposada. Però, d'acord amb les definicions, podem afirmar concloentment que en l'actualitat al municipi de Tarragona no hi ha guetos o enclavaments ètnics de població estrangera: els barris de concentració d'immigració es caracteritzen per la diversitat d'orígens i no pas per un alt grau d'homogeneïtat.

\subsection{El paper del preu de l'habitatge i les xarxes socials}

En contextos urbans, a diferència dels nivells territorials superiors en què l'estructura econòmica o el desenvolupament dels mitjans de transport són els elements explicatius de la distribució de la població estrangera (Bayona, 2007a), els factors determinants en la comprensió de les dinàmiques territorials de la immigració són els preus immobiliaris i les xarxes socials (Fullaondo, 2008).

La capacitat d'accés a l'habitatge es relaciona fortament amb els recursos econòmics que té l'immigrant. En aquest sentit, si tenim en compte les desorbitades taxes d'atur de la població immigrant $\mathrm{i}$ la precària i baixa qualificació dels llocs de treball que ocupen en el mercat laboral, no és estrany que els seus 
recursos financers siguin escassos i, per tant, les capacitats d'accés a l'habitatge, limitades. Fins ara, no hem dit res de nou pel simple fet que la població autòctona també accedeix a l'habitatge en funció del seu nivell adquisitiu. Però, al contrari de la població autòctona, en el cas d'accés a l'habitatge de la població immigrant hi influeixen altres factors (Fullaondo, 2008).

D'una banda, s'opta més pel lloguer que per la compra, encara que això ha canviat molt en els últims anys de la maleïda bombolla immobiliària; només cal veure la proporció força gran d'immigrants afectats o amenaçats actualment pel desnonament. D'altra banda, el producte que es lloga és diferent: tant pot ser un pis, una habitació o fins i tot un llit. Aquest mercat informal, popular, social... és l'únic mercat del qual es nodreix una considerable part de la població immigrant. Segons Fullaondo (2008), dues són les vies d'accés al mercat informal: els anuncis i les xarxes socials. Els anuncis són tot un clàssic $i$ se solen trobar en els establiments dels estrangers, com cafeteries, bars, locutoris, botigues de queviures, etc. Per la via de les xarxes socials, Pedone (2003) en distingeix de dos tipus: les xarxes funcionals i les xarxes d'ajuda. Les xarxes funcionals consisteixen en el traspàs d'informació entre persones per aconseguir habitatge sense que hi hagi cap vincle o predisposició d'ajuda entre la persona interessada a trobar pis i qui facilita el contacte o el llogater. Per contra, en el cas de les xarxes d'ajuda, sí que és present la predisposició d'ajuda; en són un exemple les xarxes familiars o les amistats, que ajuden la persona interessada en la cerca d'habitatge.

\subsection{Segregació i procés d'integració dels immigrants}

La interrelació entre la segregació residencial i el procés d'integració dels immigrants s'ha configurat com un dels punts destacats del desenvolupament teòric entorn de la segregació (Bayona, 2007a). En un sentit elemental i des d'una perspectiva social, entenem per integració la convivència entre la població autòctona i la població immigrant. A la literatura podem trobar diverses definicions d'integració, entre les quals destaquem la del Comitè Econòmic i Social Europeu (2002: 69), on els drets ciutadans ocupen un lloc central i els aspectes culturals passen a un segon pla. La integració és, doncs, «la progressiva equiparació dels immigrants i refugiats amb la resta de la població en drets i deures, així com també el seu accés a béns, serveis i vies de participació ciutadana en condicions d'igualtat d'oportunitats i de tracte». Generalment, s'acostuma a assumir que la segregació pot ser un factor que endarrereix el procés d'integració. No obstant això, no existeixen proves empíriques prou evidents que corroborin la relació entre segregació i no-integració en la societat dels immigrants, com assenyala Musterd (2003). Les classes socials elevades o la població estrangera provinent de països desenvolupats, molt sovint, mantenen uns elevats valors de segregació residencial, però al mateix temps estan integrats en la societat. Per contra, ens podem trobar amb situacions de segregació espacial insignificants que amaguen casos de discriminació i conflictes socials (Bayona, 2007a). 


\section{Fonts estadístiques, àmbit territorial $\mathrm{i}$ indicadors de segregació residencial}

\subsection{Fonts estadistiques}

La font utilitzada en la nostra anàlisi és el padró municipal d'habitants, registre administratiu de competència i actualització municipal que recull la relació d'habitants d'un municipi. L'any 1996, amb la Llei 4/1996 del 10 de gener, va entrar en funcionament un nou sistema de gestió continuat i informatitzat dels padrons municipals que substitueix les renovacions padronals quinquennals: és el que es coneix per padró continu. El padró continu es basa en la coordinació de tots els padrons municipals per part de l'Institut Nacional d'Estadística (INE), el qual en última instància dóna el vistiplau i remet les dades presentades pels ajuntaments un cop corregits els errors i evitades les duplicitats en els registres. Si més no, aquesta fita suposa un salt qualitatiu important, ja que permet el coneixement de la informació bàsica sobre els habitants d'un municipi de manera immediata. De 1998 ençà s'obtenen xifres oficials de població a 1 de gener de cada any, i les referides a 1 de gener de 2012 són les darreres en el moment de redactar aquest treball.

Les variables sociodemogràfiques del padró emprades en aquest estudi són les que fan referència al sexe, l'edat i la nacionalitat ${ }^{1}$, amb dades a escala municipal i inframunicipal (seccions censals) de la ciutat de Tarragona, proporcionades tant per l'INE com per l'Institut d'Estadística de Catalunya (Idescat) a 1 de gener de cada any. Cal esmentar que el fet d'utilitzar dades desagregades per seccions censals limita considerablement l'àmbit temporal de la nostra recerca, ja que per a aquest nivell de desagregació territorial només disposem de dades des de l'any 2004.

\section{2. Àmbit territorial}

L'àmbit d'estudi està predeterminat pels límits administratius del terme municipal de Tarragona i té com a base les unitats territorials inframunicipals; les onze zones urbanes $\mathrm{i}$, sobretot, les seccions censals. Les seccions censals són àrees del territori municipal molt ben delimitades que s'utilitzen com a base per al cens electoral, i per això reben la qualificació de "censal». Tot habitatge o habitant ha de pertànyer a només una d'aquestes àrees, i el seu conjunt ha de conformar la totalitat del territori municipal. La Llei orgànica 5/1985 del règim electoral general recomana que una secció censal no superi els 2.500 habitants, de manera que l'àrea màxima que pot ocupar una secció censal no està determinada per un criteri de superfície sinó pel nombre d'habitants. En

1. S'ha optat per l'ús de la variable relativa a la nacionalitat en lloc de la variable referent al país de naixement, ja que, d'una banda, l'ús d'aquesta última implicaria excloure de l'anàlisi la població nascuda al nostre país però que manté la nacionalitat marroquina, i, de l'altra, es considera que l'adquisició de la nacionalitat espanyola entre la població nascuda al Marroc és menor que no pas entre uns altres col-lectius, sobretot entre la població llatinoamericana. 


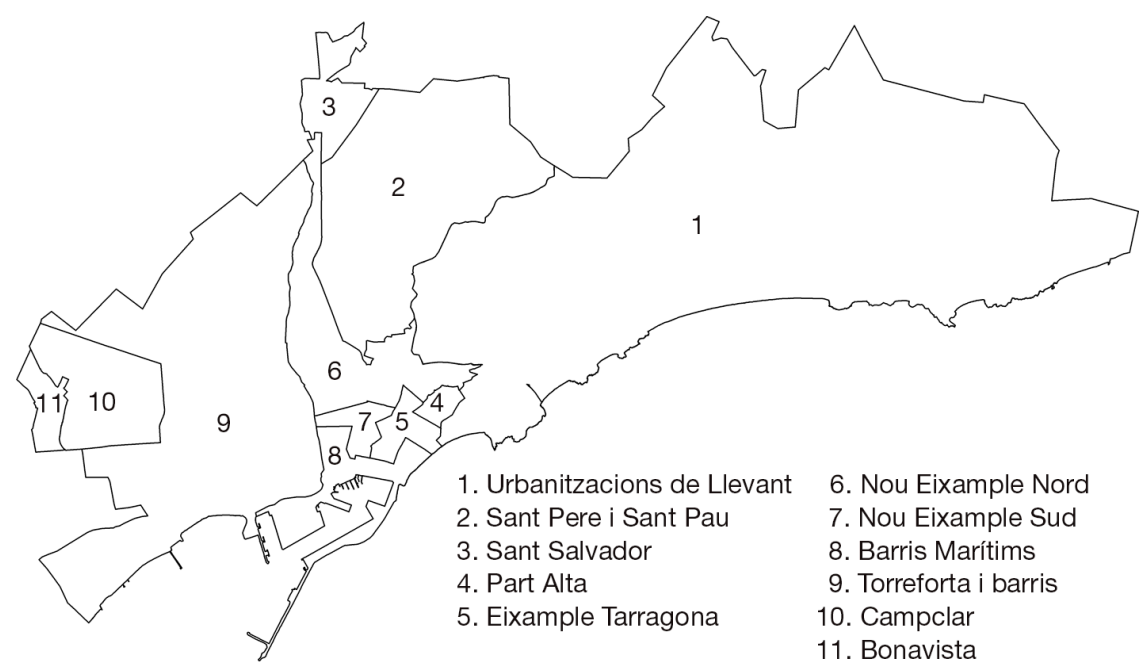

Figura 1. Tarragona i les onze zones urbanes.

Font: elaboració pròpia.

canvi, les onze zones urbanes (figura 1) sorgeixen fruit d'una divisió que fa l'Ajuntament de Tarragona tenint en compte una sèrie de criteris: el criteri d'unitat territorial (cadascuna de les onze zones no està dividida al seu interior pel que fa als barris que la configuren); el criteri d'homogeneïtat funcional o sociològica (les activitats que s'hi desenvolupen i la població que s'hi allotja són força similars); el criteri històric tampoc no s'obvia, ja que cada zona presenta una semblança en el seu període de formació; i, finalment, el volum poblacional i la utilització de les seccions censals en la seva creació també es van considerar ${ }^{2}$.

\subsection{Indicadors de segregació residencial}

La bibliografia ens ofereix una gran varietat de mesures de la segregació residencial o espacial, des dels índexs més simples fins als d'anàlisi multivariada. En el nostre cas, la segregació residencial serà copsada amb dos dels indicadors més utilitzats i imposats en la literatura científica: l'índex de segregació i l'índex de dissimilitud.

L'índex de segregació de Duncan i Duncan (1955a i 1955b) calcula la diferència entre la proporció d'individus del grup minoritari del qual s'analitza

2. Per tal d'atorgar continuïtat i coherència territorial a l'anàlisi, s'ha optat per excloure de l'estudi l'àmbit de l'actual municipi de la Canonja, creat oficialment el 30 d'octubre de 2010 per segregació respecte de Tarragona. 
la segregació i la proporció del grup majoritari (espanyols) per a cada secció censal. Els valors varien entre 0 i 1 , o bé entre 0 i 100 si els expressem en tant per cent. El valor 0 només s'obté quan a totes les seccions hi ha la mateixa proporció de població del grup minoritari i del grup majoritari, mentre que l'1 indica una distribució en l'espai de màxima segregació. El resultat d'aquest índex es pot interpretar com la proporció del grup analitzat que hauria de canviar del lloc de residència per obtenir una localització igualitària.

L'índex de dissimilitud, també creat per Duncan i Duncan (1955a i 1955b), és molt similar a l'anterior quant a la definició; la diferència rau en el fet que ara es compara la distribució de dos subgrups de població entre ells i no la localització d'un subgrup en relació amb la població total. Aquest índex presenta valors compresos entre 0 i 1, o bé entre 0 i 100 si els expressem en tant per cent. El valor 1 és sinònim de segregació màxima, $\mathrm{i}$ el 0 ens informa que les dues poblacions comparades entre si es distribueixen de forma idèntica en el territori, o, dit d'una altra manera, el valor 0 indicaria que totes les seccions censals tenen la mateixa composició que els grups relacionats, mentre que la unitat assenyalaria la inexistència de seccions on es trobin tots dos grups. També es pot interpretar de la manera següent: per exemple, si l'índex de dissimilitud dels marroquins respecte als colombians és de 0,3875, això significa que el 38,75\% dels marroquins haurien de canviar de secció censal $i$, per tant, de residència per poder estar distribuïts de manera equitativa a tota la ciutat. A continuació es presenten les formulacions dels dos índexs:

Índex de segregació:

$$
\mathrm{IS}=\frac{1}{2} \sum_{i=1}^{n}\left|\frac{x_{i}}{X}-\frac{t_{i}-x_{i}}{T-X}\right| 0 \leq I S \leq 1
$$

On $x_{i}$ és la població del grup minoritari en la secció $i$; $X$ és la població total del grup minoritari en el conjunt del municipi; $t_{i}$ és la població total en la secció $i$; $T$ és la població total del municipi, i $n$ és el nombre de seccions censals del municipi.

Índex de dissimilitud:

$$
\mathrm{D}=\frac{1}{2} \sum_{i=1}^{n}\left|\frac{x_{i}}{X}-\frac{y_{i}}{Y}\right| 0 \leq D \leq 1
$$

On $x_{i}$ és la població del grup $X$ en la secció $i$; $X$ és la població total del grup $X$ en el conjunt del municipi; $y_{i}$ és la població del grup $Y$ en la secció $i$; $Y$ és la població total del grup $Y$ en el conjunt del municipi, i $i$ és el nombre de seccions censals del municipi.

Amb l'ànim de plasmar cartogràficament la segregació o concentració relativa s'utilitza el quocient de localització o concentració, que relaciona la proporció d'una població determinada en un espai concret amb el total de 
la mateixa a la ciutat. Si el valor calculat és superior a la unitat, s'interpreta que la població està sobrerepresentada, i el cas oposat és amb els valors inferiors a la unitat. La formulació del quocient de localització és:

Quocient de localització o concentració (QL):

$$
\mathrm{QL}=\frac{x_{i}}{t_{i}} / \frac{X}{T}
$$

On $x_{i}$ és la població del grup $X$ en la unitat espacial $i$; $X$ és la població total del grup $X$ al municipi; $t_{i}$ és la població total de la unitat $i$; i $T$ és la població total del municipi.

\section{Població marroquina a Tarragona. Agrupació i segregació espacial}

\subsection{Una breu contextualització demogràfica}

Des d'inicis de segle XXI, la població de nacionalitat marroquina empadronada a la ciutat de Tarragona (taula 1 ) ha experimentat un creixement de gran magnitud. L'any 2000, escassament 419 residents marroquins estaven registrats al padró, un $0,4 \%$ del total d'habitants i un $26,6 \%$ del total de la població estrangera del municipi. Onze anys més tard, amb el padró de 2012, aquesta xifra assoleix el seu punt àlgid i se situa en 7.093 residents, un $5,3 \%$ del total d'habitants i un $28,9 \%$ del total de la població estrangera. Es tracta, doncs, d'un gran increment xifrat en 6.681 habitants, que la situa a la

Taula 1. Evolució de la població de nacionalitat marroquina a Tarragona (2000-2012)

\begin{tabular}{lcccccrr}
\hline & $\begin{array}{c}\text { Població } \\
\text { total (1) }\end{array}$ & $\begin{array}{c}\text { Població } \\
\text { estrangera (2) }\end{array}$ & Total & $\begin{array}{c}\% \\
\text { sobre (1) }\end{array}$ & $\begin{array}{c}\% \\
\text { sobre (2) }\end{array}$ & $\begin{array}{r}\text { Variació } \\
\text { absoluta }\end{array}$ & $\begin{array}{c}\text { Variació } \\
\%\end{array}$ \\
\hline 2012 & 133.954 & 24.550 & 7.093 & 5,3 & 28,9 & 234 & 3,4 \\
2011 & 134.085 & 24.191 & 6.859 & 5,1 & 28,4 & -221 & $-3,1$ \\
2010 & 140.184 & 25.494 & 7.080 & 5,1 & 27,8 & 80 & 1,1 \\
2009 & 140.323 & 25.423 & 7.000 & 5,0 & 27,5 & 1.035 & 17,4 \\
2008 & 137.536 & 22.768 & 5.965 & 4,3 & 26,2 & 912 & 18,1 \\
2007 & 134.163 & 18.585 & 5.053 & 3,8 & 27,2 & 856 & 20,4 \\
2006 & 131.158 & 15.329 & 4.197 & 3,2 & 27,4 & 1.068 & 34,1 \\
2005 & 128.152 & 12.501 & 3.129 & 2,4 & 25,0 & 1.241 & 65,7 \\
2004 & 123.584 & 8.540 & 1.888 & 1,5 & 22,1 & 608 & 47,5 \\
2003 & 121.076 & 6.222 & 1.280 & 1,1 & 20,6 & 365 & 39,9 \\
2002 & 117.184 & 3.869 & 915 & 0,8 & 23,7 & 330 & 56,4 \\
2001 & 115.153 & 2.296 & 585 & 0,5 & 25,5 & 173 & 42,0 \\
2000 & 114.097 & 1.547 & 419 & 0,4 & 26,6 & - & - \\
\hline
\end{tabular}

Font: elaboració pròpia a partir de dades de l'Idescat.

Nota: les dades corresponents al període 2000-2010 inclouen els residents de la Canonja, una zona de la ciutat de Tarragona que es va independitzar i va esdevenir un nou municipi a partir de l'any 2010. 
Taula 2. Població de nacionalitat marroquina per grans grups d'edat (2000-2012)

\begin{tabular}{|c|c|c|c|c|c|c|c|c|}
\hline \multirow[b]{2}{*}{ Grups d'edat } & \multicolumn{2}{|c|}{2000} & \multicolumn{2}{|c|}{2004} & \multicolumn{2}{|c|}{2008} & \multicolumn{2}{|c|}{2012} \\
\hline & Absoluts & $\%$ & Absoluts & $\%$ & Absoluts & $\%$ & Absoluts & $\%$ \\
\hline $0-14$ & 122 & 29,1 & 449 & 23,8 & 1.579 & 26,5 & 2.024 & 28,5 \\
\hline $15-64$ & 287 & 68,5 & 1.401 & 74,2 & 4.305 & 72,2 & 4.965 & 70,0 \\
\hline 65 i més & 10 & 2,4 & 38 & 2,0 & 81 & 1,4 & 104 & 1,5 \\
\hline Total & 419 & 100 & 1.888 & 100 & 5.965 & 100 & 7.093 & 100 \\
\hline
\end{tabular}

Font: elaboració pròpia a partir de dades de l'Idescat.

capçalera del rànquing de nacionalitats estrangeres del municipi. L'augment del nombre d'efectius es caracteritza pel fet de ser continu, però no pas regular. Les variacions anuals absolutes més agudes es donen entre els anys 2004-2005 (1.241 habitants), $2005-2006$ (1.068 habitants) i 2008-2009 (1.035 habitants); per contra, les variacions anuals relatives més importants tenen lloc entre els anys 2001-2002 (56,4\%) i 2004-2005 (65,7\%). No obstant això, l'any 2011 la població de nacionalitat marroquina coneix un lleuger descens anòmal (-221 habitants) en el nombre de residents respecte de l'any anterior.

Al mateix temps que augmenta la població, també varia la seva estructura per sexe i edat. La distribució de la població marroquina per grans grups d'edat per al període 2004-2012 (taula 2) presenta una alta concentració en les edats adultes joves (68,5\% l'any 2000, 74,2\% el 2004, 72,2\% el 2008 i $70 \%$ el 2012), que és acompanyada d'una destacada presència del grup 0-14 (29,1\% el primer any, 23,8\% el segon, 26,5\% el tercer i 28,5\% l'últim) i una escassa representació del grup de més grans de 65 anys $(2,4 \%, 2,0 \%$, $1,3 \%$ i $1,5 \%$, respectivament).

D'altra banda, l'accelerament dels fluxos comporta un rejoveniment, com també una presència més elevada d'homes resultant segurament dels darrers processos de regularització adreçats a treballadors. Les piràmides de població (figura 2) reflecteixen la clara sobrepresentació del sexe masculí, sobretot a l'interval entre els 25 i els 39 anys. L'aplicació de l'índex de masculinitat ens permet quantificar i contrastar que, en efecte, es tracta d'una distribució sensiblement masculinitzada. El grau de masculinització manté una evolució en forma de campana: comença amb un valor relativament baix l'any 2000 (113 homes per cada 100 dones), s'accentua el 2004 i el 2008 (151 i 148 homes per 100 dones, respectivament) i torna a davallar el 2012 (129 homes per 100 dones). La base piramidal destaca per la important natalitat; el tronc, per l'acumulació del gran gruix poblacional sempre masculinitzat, i la cúspide, per l'insignificant pes de la població envellida, sempre feminitzada. Ens trobem, doncs, davant d'una estructura per sexe i edat jove i en edat activa que demogràficament actua com a moderadora de la baixa natalitat i de l'augment incipient de la mortalitat — a causa de l'envelliment- de la població tarragonina. 
Any 2000

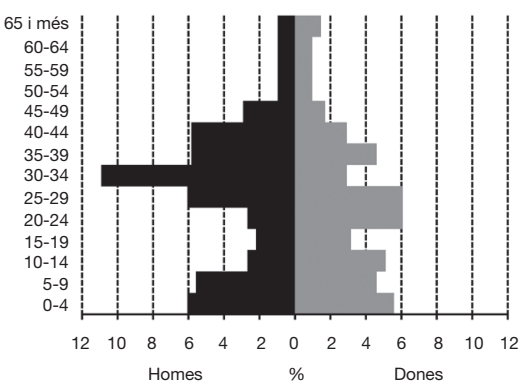

Any 2008

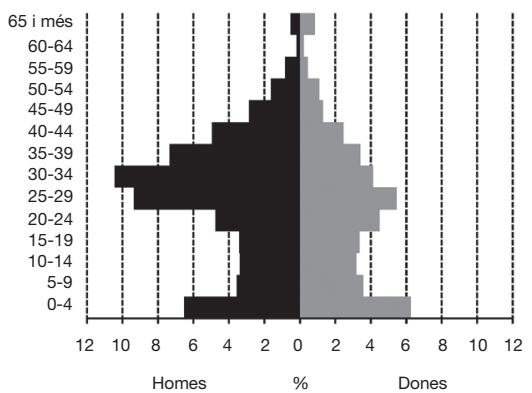

Any 2004

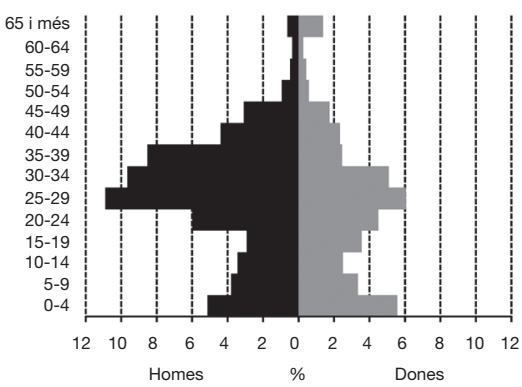

Any 2012

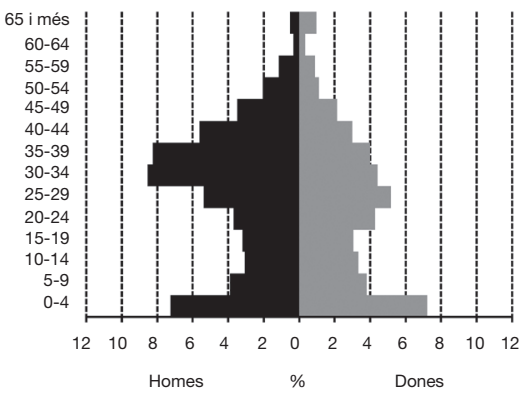

Figura 2. Població de nacionalitat marroquina per grans grups d'edat i sexe a Tarragona (2000-2012).

Font: elaboració pròpia a partir de dades de l'Idescat.

\subsection{Pautes de distribució espacial}

Prenent l'any 2004 com a punt inicial per a l'estudi de la distribució residencial de la població de nacionalitat marroquina a Tarragona (taula 3), s'observa, d'una banda, una evident concentració espacial entre Torreforta i Barris (33,9\%), Campclar (12,1\%) i Sant Salvador (13,9\%), que aglutinaven aproximadament el $60 \%$ de la població marroquina de la ciutat, i de l'altra, Sant Pere i Sant Pau $(8,5 \%)$, Barris Marítims $(8,2 \%)$ i Bonavista $(6,4 \%)$ com a zones de transició $(23,1 \%)$, mentre que a la resta de zones de la ciutat la presència de població marroquina és relativament escassa $(16,9 \%)$ en contrast amb les anteriors.

Les zones assenyalades com de major presència de població marroquina són barris periferics nascuts durant les dècades dels anys seixanta i setanta per acollir la immigració procedent de la resta d'Espanya i que progressivament ha estat substituiida per l'arribada de nova població estrangera, en un procés que hom anomena "cadena de vacants", pel qual una població es veu substituïda a mesura que prospera socialment i econòmicament per una altra de més vulnerable. 
Taula 3. Distribució de la població de nacionalitat marroquina segons la zona urbana de residència, Tarragona (2004-2012)

\begin{tabular}{|c|c|c|c|c|c|c|c|c|c|c|}
\hline & \multicolumn{2}{|c|}{2004} & \multicolumn{2}{|c|}{2006} & \multicolumn{2}{|c|}{2008} & \multicolumn{2}{|c|}{2010} & \multicolumn{2}{|c|}{2012} \\
\hline & Abs. & $\%$ & Abs. & $\%$ & Abs. & $\%$ & Abs. & $\%$ & Abs. & $\%$ \\
\hline Urbanitzacions de Llevant & 46 & 2,6 & 55 & 1,4 & 44 & 0,8 & 40 & 0,6 & 35 & 0,5 \\
\hline Sant Pere i Sant Pau & 150 & 8,5 & 241 & 6,0 & 365 & 6,4 & 397 & 5,9 & 436 & 6,1 \\
\hline Sant Salvador & 244 & 13,9 & 658 & 16,5 & 947 & 16,7 & 1.064 & 15,9 & 1.039 & 14,7 \\
\hline Part Alta & 36 & 2,1 & 93 & 2,3 & 117 & 2,1 & 121 & 1,8 & 144 & 2,0 \\
\hline Eixample Tarragona & 85 & 4,8 & 106 & 2,7 & 156 & 2,8 & 192 & 2,9 & 238 & 3,4 \\
\hline Nou Eixample Nord & 96 & 5,5 & 127 & 3,2 & 155 & 2,7 & 172 & 2,6 & 215 & 3,0 \\
\hline Nou Eixample Sud & 35 & 2,0 & 36 & 0,9 & 63 & 1,1 & 79 & 1,2 & 75 & 1,1 \\
\hline Barris Marítims & 144 & 8,2 & 192 & 4,8 & 270 & 4,8 & 311 & 4,6 & 370 & 5,2 \\
\hline Torreforta i Barris & 596 & 33,9 & 1342 & 33,6 & 1.938 & 34,3 & 2.192 & 32,7 & 2.442 & 34,4 \\
\hline Campclar & 213 & 12,1 & 735 & 18,4 & 1.018 & 18,0 & 1.299 & 19,3 & 1.249 & 17,6 \\
\hline Bonavista & 113 & 6,4 & 409 & 10,2 & 581 & 10,3 & 839 & 12,5 & 850 & 12,0 \\
\hline Total & 1.758 & 100 & 3.994 & 100 & 5.654 & 100 & 6.706 & 100 & 7.093 & 100 \\
\hline
\end{tabular}

Font: elaboració pròpia a partir de dades de l'INE.

Coincidint amb l'increment d'efectius, aquesta situació inicial evoluciona a grans trets cap a: 1) una accelerada agrupació tant en termes absoluts com relatius als barris periferics situats a la part inferior de la jerarquia residencial de la ciutat (Torreforta i Barris, Campclar, Sant Salvador i Bonavista); 2) una pèrdua del pes relatiu de les zones més ben situades socioeconòmicament (Eixample Tarragona, Nou Eixample Nord, Nou Eixample Sud i Urbanitzacions de Llevant), i 3) la transició de Sant Pere i Sant Pau i Barris Marítims acompanyada de l'estabilitat en termes relatius de la Part Alta (nucli antic de la ciutat) al llarg de tot el període d'estudi.

La concentració primerenca evoluciona i s'accentua el darrer any d'estudi. El 2012, el 78,7\% dels marroquins resideixen en tan sols quatre de les onze zones de la ciutat: Torreforta i Barris (34,4\%), Campclar (17,6\%), Bonavista (12\%) i Sant Salvador (14, 7\%). En contraposició, el 10\% entre els Eixamples, la Part Alta i les Urbanitzacions de Llevant, aquesta última la zona amb menys població de nacionalitat marroquina $(0,50 \%)$. El $11,3 \%$ restant es reparteix de forma bastant equitativa entre les denominades zones de transició: Sant Pere i Sant Pau (6,1\%) i Barris Marítims (5,2\%). Així doncs, les disparitats en la distribució territorial plasmen sobre l'espai urbà tarragoní una alta agrupació de població de nacionalitat marroquina a ponent i una certa dispersió al centre i a llevant. A diferència de la capital catalana (Bayona, 2004; Bayona i Blanco, 2004), la població de nacionalitat marroquina no es caracteritza per la concentració residencial al centre històric de la ciutat, sinó que destaca per la seva agrupació als barris periferics populars de la ciutat, emergits arran de la immigració procedent de la resta d'Espanya durant el transcurs del segle passat.

D'altra banda, i pel que fa a la proporció que representa la població de nacionalitat sobre el conjunt de residents de la zona urbana 2004-2012 (figura 3), les 

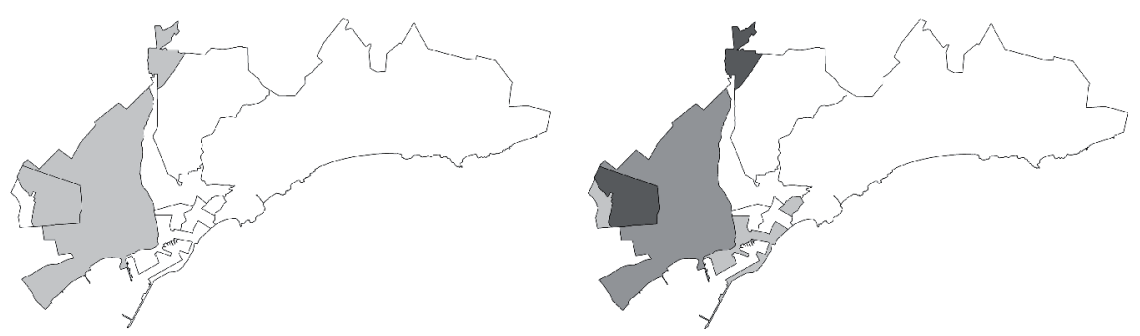

2008
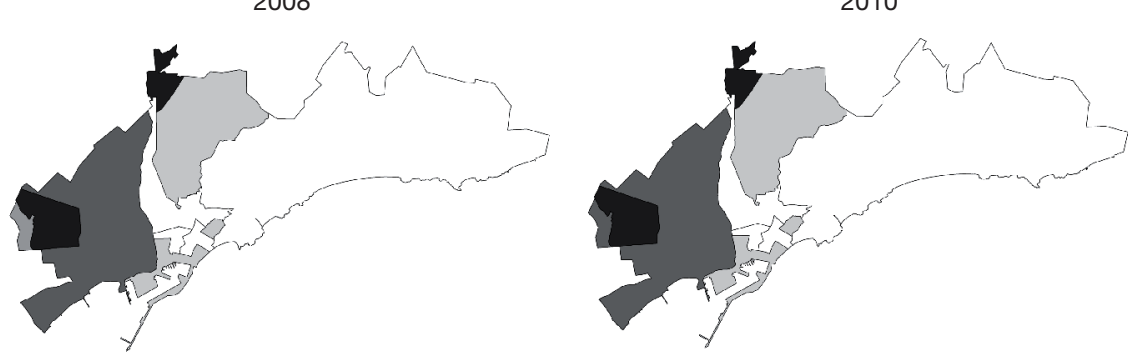

2012
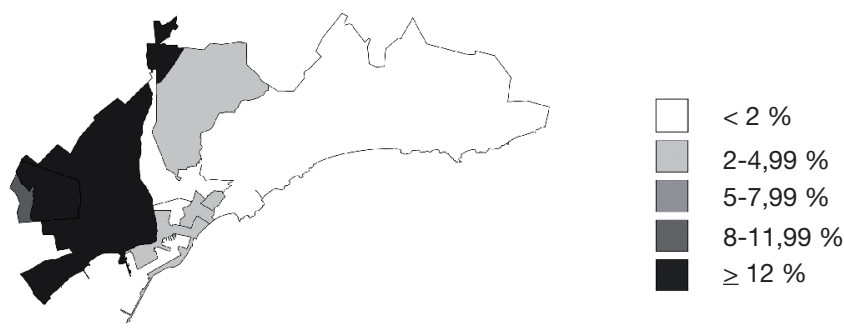

Figura 3. Proporció de residents de nacionalitat marroquina segons la zona urbana, Tarragona (2004-2012).

Font: elaboració pròpia a partir de dades de l'INE.

dades confirmen les tendències apuntades anteriorment. Els resultats obtinguts van encaminats en la mateixa direcció que els anteriors: altes proporcions a ponent i baixes al centre i a llevant. D'aquesta manera, l'any 2004, les zones de Sant Salvador (4,8\%), Torreforta i Barris $(3,6 \%)$ i Campclar $(3,1 \%)$ presentaven una proporció de població marroquina sobre el total de residents superior al 3\%, seguides de Bonavista (1,5\%) i Barris Marítims $(1,7 \%)$ i Sant Pere i Sant Pau (1,1\%), amb valors compresos entre l'1 i el 2\%, mentre que a la 
resta de zones les xifres no arriben ni a l'1\%. A partir de l'any inicial s'aprecien tres comportaments diferenciats a causa de l'increment d'efectius: 1) un augment important de les proporcions a Sant Salvador i a les zones limítrofes de Torreforta i Barris, Bonavista i Campclar; 2) un descens progressiu a les Urbanitzacions de Llevant, i 3) un increment menor a la resta de zones de la ciutat. Així, l'any 2012, Sant Salvador (14,5\%), Bonavista (9,7\%), Torreforta i Barris $(13,0 \%)$ i Campclar $(14,9 \%)$ se situen amb valors superiors al $9 \%$, les Urbanitzacions de Llevant, que l'any 2004 presentaven un valor de $0,4 \%$, ara el presenten de $0,3 \%$, i la resta de zones, tot i haver incrementat el seu valor inicial, aquest no sobrepassa l'1\% en el cas del Nou Eixample Nord (0,9\%) i Sud $(0,5 \%)$ i el $4 \%$ a la Part Alta $(3,4 \%)$, Eixample $(2,2 \%)$, Sant Pere i Sant Pau (2,7\%) i els Barris Marítims (3,7\%).

L'esquematització duta a terme presenta, per tant, una ciutat amb un únic pol d'implantació de la població de nacionalitat marroquina, que, juntament amb les zones de transició clarament marcades, abasten la meitat de les zones urbanes del municipi. A la resta de zones, a diferència de les anteriors, la població de nacionalitat marroquina és escassa o pràcticament inexistent. A tall de conclusió, podem adjectivar el model de distribució residencial de la població de nacionalitat marroquina a Tarragona com a "polaritzat».

\subsection{Segregació residencial}

En aquest apartat s'introdueixen un seguit d'indicadors quantitatius clàssics que ens informen de forma sintètica, en un únic valor, de la distribució residencial (territorial o espacial) de la subpoblació prèviament definida. Els càlculs es fan per al període 2004-2012 utilitzant com a unitats d'anàlisi les seccions censals.

L'índex de segregació, que compara la distribució d'un grup de població en relació amb la població total del municipi, apunta que els valors de segregació residencial de les principals nacionalitats estrangeres de la ciutat són heterogenis (taula 4). En el cas dels marroquins, aquests mantenen una evolució ascendent al llarg de tot el període d'estudi, que s'inicia amb el 48,8\% l'any 2004, finalitza amb una xifra del 58,9\% el 2012, i assoleix el seu valor màxim l'any 2010 amb una segregació del 59,8\%. L'increment de deu punts percentuals entre el principi i el final d'etapa en el grau de segregació no és gens sorprenent vist el procés de concentració patent en comptats barris de la ciutat: l'augment del nombre d'efectius no ha suposat una reducció en els nivells de segregació sinó tot el contrari.

És cert que, entre tots els col-lectius estrangers, la nacionalitat marroquina és l'única que augmenta significativament el seu valor de segregació al llarg del període temporal d'estudi; però tot i així, en comparació amb l'evident model de segregació residencial que mostren nacionalitats com la nigeriana, o bé amb la pauta d'escassa segregació d'algunes nacionalitats sud-americanes (argentins i colombians, principalment) i europees (italians i francesos), la comunitat marroquina pot ser considerada, segons la segregació revelada, «segregada amb 
Taula 4. Índex de segregació de les principals nacionalitats estrangeres a Tarragona (2004-2012)

\begin{tabular}{lrrrrr}
\hline & 2004 & 2006 & 2008 & 2010 & 2012 \\
\hline Marroc & 48,8 & 55,3 & 57,0 & 59,8 & 58,9 \\
Romania & 51,6 & 40,4 & 41,2 & 40,0 & 37,5 \\
Colòmbia & 31,9 & 33,1 & 31,3 & 32,9 & 31,3 \\
Xina & - & 47,1 & 50,2 & 51,5 & 46,4 \\
Nigèria & - & - & 68,3 & 69,7 & 68,6 \\
Itàlia & - & 31,6 & 29,3 & 29,0 & 31,7 \\
Argentina & 38,7 & 34,0 & 32,9 & 32,0 & 30,3 \\
Bulgària & - & 49,1 & 44,3 & 44,9 & 41,2 \\
Equador & 52,5 & 46,6 & 46,5 & 42,4 & 44,4 \\
Pakistan & - & - & 70,9 & 68,5 & 58,8 \\
Bolívia & - & 57,2 & 48,4 & 52,9 & 54,2 \\
França & 40,1 & 39,9 & 37,1 & 36,8 & 36,3 \\
Algèria & - & - & 51,2 & 52,4 & 47,9 \\
\hline
\end{tabular}

Font: elaboració pròpia a partir de dades de l'INE.

nivells mitjans». En aquest sentit, els marroquins de Tarragona mostren un grau de segregació semblant al que troba Bayona (2004 i 2007a) a la ciutat de Barcelona.

L'explicació d'aquest fet es deu a un conjunt de factors explicatius, com ara l'antiguitat de la migració i qüestions ètniques i socioeconòmiques. Vegem-les d'una en una de forma més detallada: tradicionalment, la migració marroquina ha estat la pionera entre les migracions internacionals, amb una ja llarga història de prop de vint-i-cinc anys de presència a les nostres terres, la qual cosa explicaria en part, d'una banda, la seva elevada presència al conjunt del territori català i, de l'altra, els actuals processos de reagrupament dels familiars dels immigrants ja establerts al nostre país. Encara que els treballs sobre la distribució territorial de la població mencionats en l'estat de la qüestió mostren que l'arribada massiva de nova població i la seva dispersió al territori urbà han estat processos paral.lels, sí que sembla probable que la principal via d'entrada actual al nostre país, com és el reagrupament familiar, pot fer incrementar la concentració espacial observada, ja que els nous residents arribats per aquesta via lògicament no constituiran, almenys de moment, noves llars en hipotètiques noves localitzacions, sinó que engrossiran les ja existents (Fullaondo, 2008). Probablement no és una qüestió que podem contestar amb seguretat en aquest moment, quan el recent boom migratori al nostre país no ens ofereix encara la perspectiva temporal suficient per observar què succeeix territorialment, amb el pas del temps, amb col-lectius d'arribada recent.

En relació amb les qüestions ètniques, la diferenciació territorial de la població pot deure's igualment a processos endògens d'agrupació: determinats col-lectius - especialment els que, per motius de llengua, religió o altres pautes culturals, es diferencien més de la societat d'acolliment - tendeixen a 
Taula 5. Índex de dissimilitud de la població marroquina respecte de les principals nacionalitats estrangeres, Tarragona (2004-2012)

\begin{tabular}{lrrrrr}
\hline & 2004 & 2006 & 2008 & 2010 & 2012 \\
\hline Romania & 50,8 & 57,8 & 56,8 & 57,8 & 56,6 \\
Colòmbia & 44,3 & 47,9 & 47,2 & 49,0 & 50,7 \\
Xina & - & 74,5 & 77,7 & 75,9 & 73,3 \\
Nigèria & - & - & 30,2 & 29,5 & 28,9 \\
Itàlia & - & 69,4 & 69,9 & 70,0 & 72,2 \\
Argentina & 56,4 & 59,2 & 61,9 & 59,7 & 60,6 \\
Bulgària & - & 50,9 & 43,0 & 48,6 & 52,0 \\
Equador & 60,7 & 56,1 & 49,0 & 51,3 & 52,1 \\
Pakistan & - & - & 70,6 & 59,9 & 56,9 \\
Bolívia & - & 78,4 & 72,7 & 75,8 & 76,4 \\
França & 69,4 & 71,2 & 72,4 & 74,8 & 73,5 \\
Algèria & - & - & 48,9 & 46,0 & 45,5 \\
\hline
\end{tabular}

Font: elaboració pròpia a partir de dades de l'INE.

reagrupar-se en determinats hàbitats urbans per poder recrear una atmosfera familiar que els faciliti la vida diària i on se sentin còmodes i menys estranys. Finalment, cal destacar el paper que el desigual accés a l'habitatge té sobre la distribució territorial dels diferents col-lectius nacionals: la discriminació és el principal mecanisme en la diferenciació social de l'espai basada en l'etnicitat: la reducció de les oportunitats d'elecció residencial — des d'un punt de vista social, però també des de la perspectiva geogràfica - implica, necessàriament, una segregació territorial més gran. I és probablement el col-lectiu marroquí - per qüestions que no analitzarem aquí- el que més pateix aquesta discriminació, basada sovint en discursos xenòfobs sustentats sobre estereotips falsos.

Quant a l'índex de dissimilitud (taula 5), que compara la distribució de dos subgrups de població entre si - $\mathrm{i}$ amb el qual es pot saber si comparteixen en major o menor grau el territori-, els marroquins manifesten una major relació amb els algerians i, sobretot, amb els nigerians. L'any 2012, només el 28,9\% dels nigerians haurien de canviar de secció censal de residència pel fet de tenir una distribució uniforme respecte als marroquins, ja que ambdós grups comparteixen una agrupació especial als barris de ponent de la ciutat. A l'extrem oposat, trobem molt poca compartició de l'espai amb els ciutadans bolivians, xinesos, italians i francesos, més del 70,0\% dels quals, el mateix any (2012), hauria de canviar de residència per obtenir una disposició al territori idèntica en comparació amb els ciutadans marroquins.

El mateix indicador ens permet contrastar que els espanyols nascuts a la resta d'Espanya comparteixen més l'espai residencial amb els marroquins que no pas els nascuts a Catalunya (taula 6). Les xifres al llarg d'aquests anys oscil.len entre el 56,0\% i el 58,3\% de catalans que haurien de canviar de secció de residència per aconseguir una distribució uniforme respecte del nostre grup, enfront del 48,0\% - 49,2\% de la població nascuda a la resta de 
l'Estat espanyol. Aquestes xifres proporcionades per l'índex de dissimilitud no ens haurien de generar cap estupefacció i queden més que justificades pel nombrós assentament de la comunitat marroquina als barris d'immigració espanyola. Així doncs, sembla que els penúltims a arribar a Tarragona comparteixen més que els nascuts a Catalunya l'espai residencial amb el nostre subgrup poblacional.

Taula 6. Índex de dissimilitud de la població de nacionalitat marroquina respecte dels espanyols, segons el lloc de naixement, Tarragona (2006-2012)

\begin{tabular}{lllll} 
& 2006 & 2008 & 2010 & 2012 \\
Catalunya & 56,0 & 56,7 & 58,3 & 57,1 \\
Resta d'Espanya & 48,0 & 48,0 & 49,2 & 49,2 \\
\hline
\end{tabular}

Font: elaboració pròpia a partir de dades de l'INE.

La simple distribució percentual de la població de nacionalitat marroquina segons els barris on resideix ens perfila les principals pautes residencials del col-lectiu en qüestió. Si fem un pas endavant en l'escala de desagregació territorial i descendim al nivell de secció censal, els claps de concentració i de molt baixa presència es concreten $\mathrm{i}$ a vegades revelen distribucions irregulars dins una mateixa zona urbana. Això mateix es determina mitjançant la representació del quocient de localització (figura 4), indicador de segregació residencial que relaciona la proporció de població de nacionalitat marroquina en una secció censal amb la proporció mitjana al conjunt del municipi, i que indica les àrees amb sobrerepresentació i subrepresentació.

La població de nacionalitat marroquina mostra una clara pauta d'inserció a la ciutat caracteritzada per una evident continuïtat territorial entre les seccions censals del barris amb sobrerepresentació (Torreforta i Barris, Campclar, Bonavista i Sant Salvador), que destaquen pel creixement de la població estrangera des que es va iniciar el boom immigratori. Però dins dels mateixos barris observem algunes discrepàncies que es tornen insignificants amb el transcurs dels anys i l'increment del nombre d'efectius. A l'extrem oposat, les seccions censals del centre de la ciutat presenten una patent subrepresentació que s'extrema a mesura que ens estenem cap als barris de llevant. Entre aquestes dues realitats ben distants trobem el perfil intermedi als Barris Marítims i Sant Pere i Sant Pau, on conviuen seccions amb sobrerepresentació i subrepresentació de població marroquina.

En resum, les dades proporcionades per l'índex de segregació conjuntament amb els mapes del quocient de localització ens permeten afirmar que els residents de nacionalitat marroquina a Tarragona presenten un model territorial d'inserció d'alta concentració i de considerable segregació. 

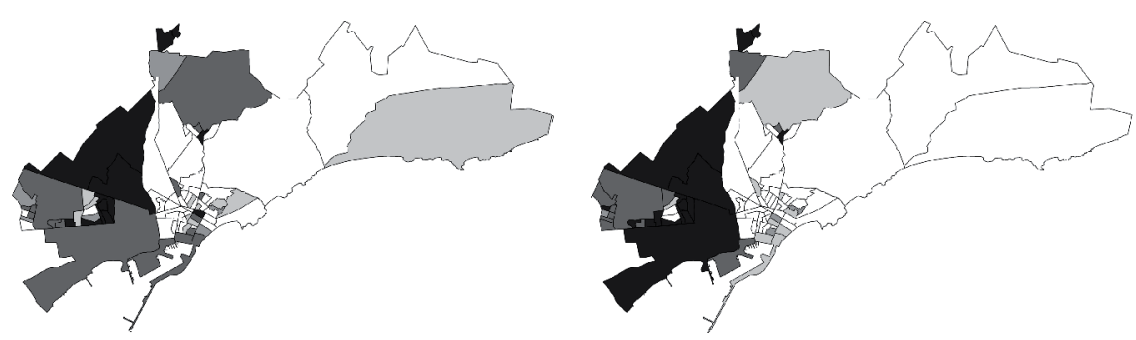

2008
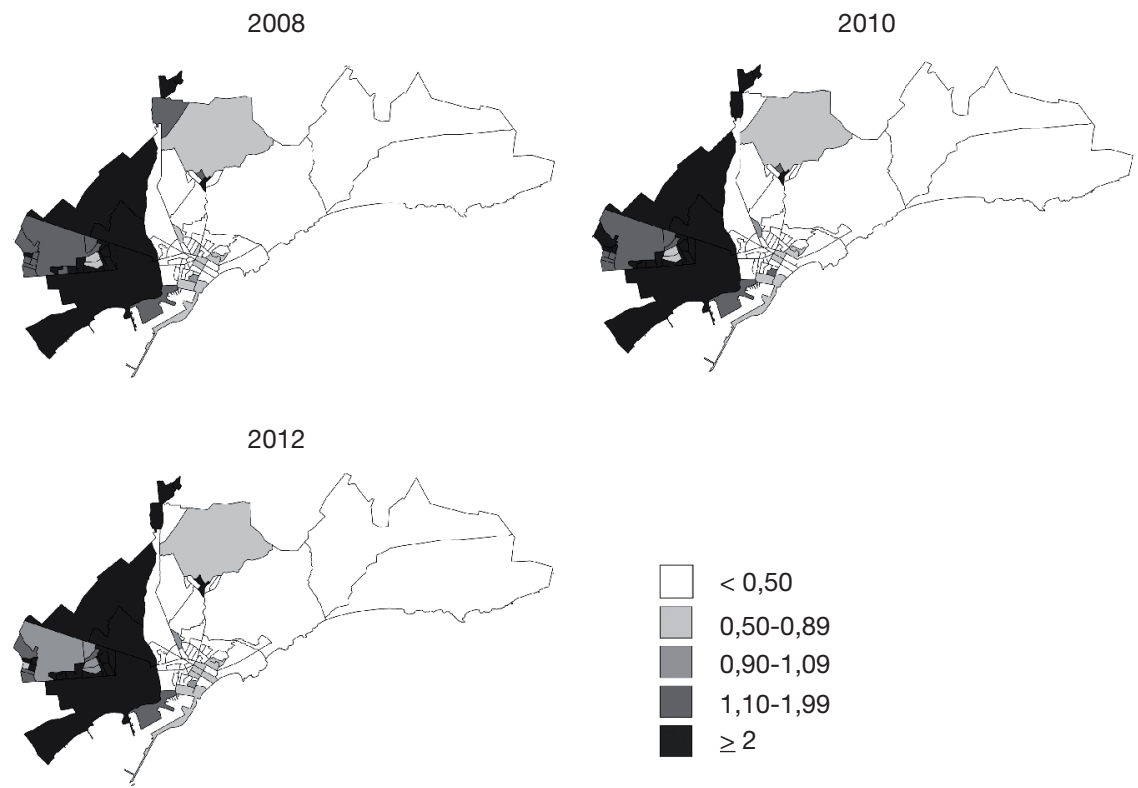

Figura 4. Quocient de localització de la població de nacionalitat marroquina a Tarragona (2004-2012).

Font: elaboració pròpia a partir de dades de l'INE.

\section{Conclusions}

Al llarg del període temporal que abasta l'estudi de la distribució espacial de la població de nacionalitat marroquina s'observa una clara pauta d'inserció al territori del col-lectiu caracteritzada per un progressiu i accelerat procés d'agrupació endògena en determinades zones de la ciutat. La successió dels anys i l'increment continuat del nombre d'efectius consolida, així, una àrea de concentració, en detriment de les zones més ben posicionades socioeconòmi- 
cament, que integra els barris periferics de Torreforta (i adjacents), Campclar, Bonavista i Sant Salvador, emergits arran de la immigració procedent de la resta d'Espanya durant el transcurs del segle passat i que se situen a la part inferior de la jerarquia residencial de la ciutat.

L'aplicació de l'índex de segregació ens permet contrastar que la dispar distribució en el territori, acompanyada de l'increment d'efectius, es tradueix directament en l'augment progressiu dels nivells de segregació residencial de la població de nacionalitat marroquina al llarg del període temporal d'estudi (2004-2012); una major concentració en l'espai implica un major grau de segregació. Tot i la tendència ascendent apreciada en els valors de segregació, en comparació amb el model de segregació residencial que mantenen les principals nacionalitats de la ciutat, podem afirmar que aquests són considerables però no alarmants.

Els resultats de l'índex de dissimilitud revelen que els espanyols nascuts a la resta d'Espanya comparteixen més que no pas els nascuts a Catalunya l'espai residencial amb la comunitat marroquina, fet que no sorprèn gaire vista la voluminosa agrupació de la població de nacionalitat marroquina als barris on es van establir els penúltims d'arribar. Al mateix temps, el col.lectiu en qüestió manté una major relació residencial amb els algerians i, sobretot, amb els nigerians, amb qui comparteix una distribució territorial força similar. Per contra, amb les principals nacionalitats procedents de països europeus, francesos i italians, i d'altres provinents de països en vies de desenvolupament, xinesos i bolivians, l'espai residencial pràcticament no es comparteix.

Tot apunta que la crisi econòmica potenciarà els processos d'agrupació i segregació en l'espai de les poblacions estrangeres més desafavorides, com és el cas del col-lectiu que analitzem aquí. Els resultats del treball ens arrosseguen a afirmar que en un futur immediat els valors de segregació continuaran creixent fruit de tres processos: el creixement natural, la migració interna de la població d'estudi i, en menor mesura, els tímids processos de reagrupament familiar. Descartem o reduïm, així, la possibilitat que aquests valors experimentin la tendència contrària tant per un possible «efecte retorn» al país d'origen a causa de la mala situació econòmica que pateix el grup, com per l'emigració cap a altres destinacions europees més atractives. Aquesta darrera opció exigeix eminentment l'adquisició de la nacionalitat del país receptor, en aquest cas l'espanyola. Si bé aquests serien processos de naturalesa demogràfica que contribuirien a uns determinats nivells de segregació, n'hi ha d'altres que, com hem vist al llarg de l'estudi, tenen un paper cabdal: la discriminació laboral, de la qual es deriva forçosament la discriminació en l'accés a l'habitatge. En tot cas, caldrà esperar a tenir noves dades per poder confirmar o desmentir aquestes afirmacions.

El treball dóna resposta a una sèrie d'interrogants, però n'obre uns altres. És pertinent manifestar que la literatura científica sobre la segregació i agrupació territorial o residencial de la població estrangera a la ciutat de Tarragona és pràcticament inexistent $i$, per consegüent, estendre l'estudi realitzat a la resta de nacionalitats del municipi seria una fita força interessant, ja que es tracta d'un camp de recerca encara per descobrir. Finalment, un aprofundiment més gran 
en aquesta mateixa investigació hauria de permetre determinar si som realment davant d'un procés de substitució poblacional protagonitzat pels penúltims i els últims d'arribar a les àrees de concentració de població de nacionalitat marroquina.

\section{Referències bibliogràfiques}

Arbaci, Sonia (2007). «Ethnic segregation, housing systems and welfare regimes in Europe». European Journal of Housing Policy, 7 (4), 401-433. $<$ http://dx.doi.org/10.1080/13691830903387378>

- (2008). «(Re)Viewing Ethnic Residential Segregation in Southern European Cities: Housing and Urban Regimes as Mechanisms of Marginalisation». Housing Studies, 23 (4), 589-613.

Arbaci, Sonia i Malheiros, Jorge (2010). «De-segregation, suburbanisation and social exclusion of immigrants - Southern European Cities in the 1990s». Journal of Ethnic and Migration Studies, 36 (2), 227-255.

BAYONA, Jordi (2007a). «La segregación residencial de la población extranjera en Barcelona: ¿̨una segregación fragmentada?». Scripta Nova: Revista Electrónica de Geografía y Ciencias Sociales, XI (235).

- (2007b). «Distribució territorial i característiques sociodemogràfiques de la població de nacionalitat estrangera en àmbits urbans: el cas de la ciutat de Barcelona». Treballs de la Societat Catalana de Geografia, 64, 7-33.

Bayona, Jordi i Blanco, Maria José (2004). "Pautes d'associació en l'espai de la població de nacionalitat estrangera a Barcelona». Documents d'Anàlisi Geogràfica, 43, 107-122.

BAyOnA, Jordi i López, Antonio (2011). "Concentración, segregación i movilidad residencial de los extranjeros en Barcelona». Documents d’Anàlisi Geogràfica, 57 (3), 381-412.

Bolt, Gideon; Hooimeijer, Pieter i Kempen, Ronald (2002). «Ethnic segregation in the netherlands: new patterns, new policies?». Tijdschrift Voor Economische en Sociale Geografie, 93 (2), 214-220. <http://dx.doi.org/10.1111/1467-9663.00196>

BRUn, Jacques (1994). «Essai critiques sur la notion de ségrégation et sur son usage en géographie urbaine». A: Brun, Jacques i Rhein, Catherine. La ségrégation dans la Ville. París : L’Harmattan, 21-57.

BuRgESs, Ernest (1928). "Residential segregation in american cities». Annals of the American Academy of Political and Social Science, 140, 105-115. $<$ http://dx.doi.org/10.1177/000271622814000115>

CheCA, Juan Carlos i ARjona, Ángeles (2007). «Factores explicativos de la segregación residencial de los inmigrantes en Almería». Revista Internacional de Sociología, LXV (48), 173-200.

Checa, Juan Carlos; Arjona-Garrido, Ángeles; Checa-Olmos, Francisco (2011). «Segregación residencial de la población extranjera en Andalucía, España». Papeles de Población, 17 (70), 219-246.

Comité Económico y Social Europeo (2002). Inmigración, asilo e integración social. Luxemburg: Oficina de Publicacions Oficials de les Comunitats Europees.

Deurloo, Marinus i Musterd, Sako (1998). «Ethnic clusters in Amesterdam, 194496: a Micro-area analysis». Urban Studies, 35 (3), 385-396. 
<http://dx.doi.org/10.1080/0042098984826>

Domingo, Andreu; Galeano, Juan i Sabater, Albert (2013). «Enclavaments ètnics a Catalunya, el País Valencià i les Illes Balears». L'Avenç, 391, 36-45.

Duncan, Otis i Duncan, Beverly (1955a). «A methological analysis of segregation indexes». American Sociological Review, 29 (3), 210-217. <http://dx.doi.org/10.1086/221609>

- (1955b). «Residential distribution and occupational stratification». American Journal of Sociology, 60 (5), 493-503.

Echazarra, Alfonso (2009). Políticas públicas y segregación residencial de la población extranjera en la Comunidad de Madrid. Madrid: Fundación Alternativas.

- (2010). «Segregación residencial de los extranjeros en el área metropolitana de Madrid. Un análisis cuantitativo». Revista Internacional de Sociología, 68 (1), 165-197. <http://dx.doi.org/10.3989/ris.2007.11.12>

Fullaondo, Arkaitz (2008). «Epíleg. Una interpretació per a la comprensió». A: Martori, Joan Carles i Hoberg, Karen. Immigrants a les ciutats. Segregació i agrupació territorial de la població estrangera a Catalunya. Barcelona: Fundació Jaume Bofill - Editorial Mediterrània, 150-180.

Guermond, Yves i Lajoie, Gilles (1999). «De la mesure en géographie sociale». L'Espace Géographique, 28 (1), 84-90. <http://dx.doi.org/10.3406/spgeo.1999.1223>

JaKubS, John (1981). "A distance based segregation index». Socio-Economic Planning Sciences, 15 (3), 129-136. <http://dx.doi.org/10.1016/0038-0121(81)90028-8>

Kempen, Ronald i Özüekren, Sule (1998). "Ethnic segregation in cities: new forms and explanations in a dynamic world». Urban Studies, 35 (10), 1631-1656. <http://dx.doi.org/10.1080/0042098984088>

Lavía, Cristina (2008). «La segregación residencial de la población extranjera de Bilbao». ACE: Arquitectura, Ciudad y Entorno, 8, 65-92.

- (2009). «Inmigración extranjera en Bilbao: una aproximación a la medida de la segregación residencial». Zerbitzuan, 45, 83-98.

Malheiros, Jorge (2002). "Ethni-cities: Residential patterns in the Northern European and Mediterranean metropolises. Implication for Policy Design». International Journal of Population Geography, 8 (2), 107-134. <http://dx.doi.org/10.1002/ijpg.247>

- (2004). "Immigration and city change: the Lisbon metropolis at the turn of the twentieth century». Journal of Ethnic and Migration Studies, 30 (6), 10651086. <http://dx.doi.org/10.1080/1369183042000286250>

Maloutas, Thomas i Fujita, Kuniko (2012) (ed.). Residential segregation in comparative perspective. Farnham: Ashgate.

Martínez, Almudena i Leal, Jesús (2008). «La segregación residencial, un indicador espacial confuso en la representación de la problemática residencial de los inmigrantes económicos: el caso de la Comunidad de Madrid». ACE: Arquitectura, Ciudad y Entorno, 8, 53-64.

Martori, Joan Carles i Hoberg, Karen (2008). Immigrants a les ciutats. Segregació i agrupació territorial de la població estrangera a Catalunya. Barcelona: Fundació Jaume Bofill - Editorial Mediterrània.

Massey, Douglas i Denton, Nancy (1988). «The dimensions of residential segrega- 
tion». Social Forces, 67 (2), 281-315.

Morgan, B. S; (1975). «The segregation of socio-economic groups in urban areas: a comparative analysis». Urban Studies, 12 (1), 47-60. <http://dx.doi.org/10.1080/00420987520080041>

MorriLl, R. L. (1991). «On the measure of geographical segregation». Geography Research Forum, 1 (11), 25-36.

Musterd, Sako (2003). «Segregation and integration: a contested relationship». Journal of Ethnic and Migration Studies, 29 (4), 623-641. <http://dx.doi.org/10.1080/1369183032000123422>

PARK, Robert Ezra (1924) «The Concept of Social Distance As Applied to the Study of Racial Attitudes and Racial Relations». Journal of Applied Sociology, 8. 339-344.

Peach, Ceri (1996a). «Good segregation, bad segregation». Planning Perspectives, 11 (4), 379-398. $<$ http://dx.doi.org/10.1080/026654396364817>

- (1996b). «Does Britain have ghettos?». Royale Geographical Society, 21 (1), 216-235.

Pedone, Claudia (2003). «Tú siempre jalas a los tuyos. Cadenas y redes migratorias de las familias ecuatorianas hacia España». Bellaterra: Universitat Autònoma de Barcelona. Departament de Geografia. Tesi doctoral.

Sabater, A., Bayona, J. i Domingo, A. (2012) «Internal migration and residential patterns across Spain after unprecedented international migration». A: Finney, N.; Catney, G. (eds.), Minority internal migration in Europe. Ashgate: Farnham, 293-311.

Sabater, A.; Domingo, A. i Galeano, J. (2013) «La transformación de las comunidades mayoritarias y la formación y evolución de los enclaves étnicos en España», Migraciones, 34: 11-44.

White, Michael (1983). «The mesurement of spatial segregation». American Journal of Sociology, 88 (5), 1008-1018. $<$ http://dx.doi.org/10.1086/227768>

Wirth, Louis (1928). The ghetto. Chicago: Transaction Publishers.

Wong, David W. S. (1993). «Spatial indices of segregation». Urban Studies, 30 (3), 559-572. <http://dx.doi.org/10.1080/00420989320080551> 